\title{
A Study of Tunnel Construction Environment Based on the TBM and Improved Methods
}

\author{
Wu Qiujun ${ }^{1}$, Li Ke ${ }^{1}$, Wang Mingnian¹, Chao Feng ${ }^{1 \mathrm{a}}$ \\ 1. MOE Key Laboratory of Transportation Tunnel Engineering, School of Civil Engineering, \\ Southwest Jiaotong University, Chengdu 610031, China
}

fengchao0217@yahoo.com

Keywords: TBM tunnel, construction environment, field tes

Abstract: With the increase of single tunnel length, traditional tunnel construction method can't meet the requirements of the construction environment. In this paper, the control values of temperature, humidity and wind speed are gained by statistics and analysis. Based on the field test of the TBM tunnel construction environment, this paper puts forward the problems existing in the construction of the tunnel, and puts forward the corresponding improvement suggestions.

\section{Definition and Classification of Tunnel Environment}

1.1 Definition of Tunnel Environment. The microclimate in the tunnel construction environment is called the tunnel climate. The main parameters of tunnel climate are temperature, humidity and wind speed in tunnel, which are the three elements of the tunnel climate. Different climatic conditions of tunnel are formed by different combinations of the elements. Health, safety, labor efficiency and comfort of workers in tunnel are effected by tunnel climate directly.

\subsection{Main Specification of Tunnel Construction Environment}

1.2.1 Related Specifications of China. The current implementation of railway tunnel construction is "code for construction of railway tunnel"( TB10204) issued by the Ministry of Railways in 2002 [1], which provides standards of temperature and wind speed in tunnel construction. Temperature in tunnel shall not exceed 28 degrees Celsius. Wind speed shall not less than $0.15 \mathrm{~m} / \mathrm{s}$ in the full-face excavation tunnel and wind speed shall not less than $0.25 \mathrm{~m} / \mathrm{s}$ in tunnel, both of which should not exceed $6 \mathrm{~m} / \mathrm{s}$. Highway tunnel construction is currently implementing the "highway tunnel ventilation lighting design specification" (JTGF60-2009) issued by the Ministry of transport [2], which provides the same standards of temperature and wind speed as the "code for construction of railway tunnel". Specific provisions of humidity are not found in both of them.

1.2.2 Related Specifications of Foreign Countries. The provisions of relevant norms of temperature is almost the same between foreign countries and the domestic specifications. Specific provisions of the humidity is also not found in specifications of foreign countries. Provisions of wind speed are as follows:

(1) "Coal mine ventilation regulations" of USA requires an average wind speed of $0.30 \mathrm{~m} / \mathrm{s}$ which based on the full section without considering the equipment occupation of space. The wind speed shall exceed $0.61 \mathrm{~m} / \mathrm{s}$ when controlling of dust which is proved by research results that the wind speed can control the dust very well.

(2) The International Tunnelling Association(ITA) provides that the amount of air or the discharge from the operating surface is that the minimum average wind speed of the full cross section tunnel or shaft shall be between $0.3 \mathrm{~m} / \mathrm{s}$ and $2 \mathrm{~m} / \mathrm{s}$ at any time.

(3) "Code for Practice of Safety in Tunneling in the Construction Industry" (BS6164 - 2001)of UK provides that dust will be upwind diffusion when the wind speed is less than $0.5 \mathrm{~m} / \mathrm{s}$. Therefore, this value is used as the minimum standard for the wind speed.

\subsection{Mechanism of Influence of Human Body Effected by Tunnel Construction Environment} 1.3.1 The Influence of Temperature

(1) The influence of low temperature

Low-temperature environment will have an adverse impact on staff efficiency when temperature 
below 10 degrees Celsius. In the low temperature environment, human body will be in the super cooled state when the central body temperature of the human body is lower than 35 degrees Celsius, which will have the following impacts on human body:

1) Human body in low temperature environment will cause frostbite partly when exposure time is not long.

2)Human body can rely on their own temperature control system so that the body deep temperature remained stable. But a longer exposure time, the center temperature gradually reduced, there will be breathing and heart rate accelerate, tremor, headache and so on a series of symptoms of hypothermia. When the temperature drops to 30 to 33 degrees Celsius, the muscles become stiff trembling, lose heat effect, will lead to death. In the low temperature and high humidity conditions of labor (such as workers of the freezer) easily cause myalgia, myositis, nerve pain, neuritis, lumbago and rheumatic diseases such as for a long time.

(2) The influence of high temperature

In a high temperature environment, the skin temperature rises with the ambient temperature rapidly increased, the body only through evaporation heat, sweating can lead to dehydration and excessive sweating can also cause water and salt metabolism disorders. High temperatures also make increased cardiac output, peripheral vascular dilation, blood flow away from the internal organs to the skin and muscles, which affects the blood supply to internal organs, leading to further digestive system, urinary system, nervous system, endocrine system and the immune system as well as biochemical functional change. For a long time at a high temperature environmental exposure can cause fever, including systemic heat stroke, heat exhaustion, skin diseases and mental disorders. Operating in high temperature environment conditions, will not only cause human discomfort, affecting their health, but also with increasing temperature and decreasing air velocity, the working efficiency will be significantly reduced. In addition, the accident rate and temperature are also related. According to the research results, accident rate is lowest when temperature around 20 degrees Celsius, when the temperature is above 28 degrees Celsius or falls below 10 degrees Celsius, accident rate will increase by $30 \%$.

1.3.2 The Influence of Humidity. Impact of humidity on people working and living environment is also great. Humidity and temperature are closely related. Humidity changes with temperature very obvious, which considered the bonding temperature basically. From the point of view of personnel health, germ breeding speed is the fastest when the relative humidity is higher than $65 \%$ or less than $38 \%$. The bacteria mortality rate is higher when the relative humidity is between $45 \%$ to $55 \%$. The suitable relative humidity was $40 \%$ in winter, $50 \%$ in summer, and $45 \%-65 \%$ in other seasons ([4-5]).

1.3.3 The Influence of Wind Speed. Wind speed is mainly affected by the body's convection heat[6-7]. When the air temperature below body temperature, the wind speed increases the convection increases. When the air temperature is equal to body temperature, convective heat transfer is completely stopped, which is not affected by the wind speed. When the air temperature is higher than body temperature, the body can not only heat, but too hot, and the air flow rate the greater the faster the heat gain. The influence of wind speed spectrum on the thermal comfort of human body is mainly studied:

(1) The wind speed spectrum curve is closer to the natural wind, then the hair is more easy to be received, that is, the more comfortable;

(2) The upper limit value of the human body to the fluctuation of wind speed is about $1 \mathrm{~Hz}$, and the lower limit value is $0.244 \sim 0.488 \mathrm{~Hz}$;

(3) The comfort requirements can be achieved by simulating the natural wind spectrum to adjust the wind speed (8-9]).

The tunnel constr[uction environment should not be more than 28 degrees Celsius temperature. Humidity should not be greater than $70 \%$. Wind speed should not be less than $0.25 \mathrm{~m} / \mathrm{s}$ and not higher than $6 \mathrm{~m} / \mathrm{s}$. 


\section{Field Test}

In the beginning of September, the author participated in the project of the construction environment of Qinling Mountains special water tunnel. The full length of Qinling Mountains drinking water tunnel is $81.58 \mathrm{~km}$, which construction environment is representative.

2.1 Engineering Background. The project is located in the Qinling ridge area to the north and humid in the South and North, transitional climate and cold in winter, cool in summer, the seasons and the weather changes larger, 8-9 month for rainy periods. The annual average temperature is 12.7 degrees Celsius, extreme maximum temperature is 40.6 degrees Celsius, and extreme minimum temperature is -20.2 degrees Celsius. The average annual precipitation is $650.5 \mathrm{~mm}$, annual mean evaporation is $985 \mathrm{~mm}$. The maximum wind speed is $13 \mathrm{~m} / \mathrm{s}$, which direction is northwest. The maximum snow depth is $20 \mathrm{~cm}$. Soil maximum freezing depth is $24 \mathrm{~cm}$.

The maximum height of the tunnel through the lot is $2540 \mathrm{~m}$. The maximum depth of the tunnel is $1990 \mathrm{~m}$.

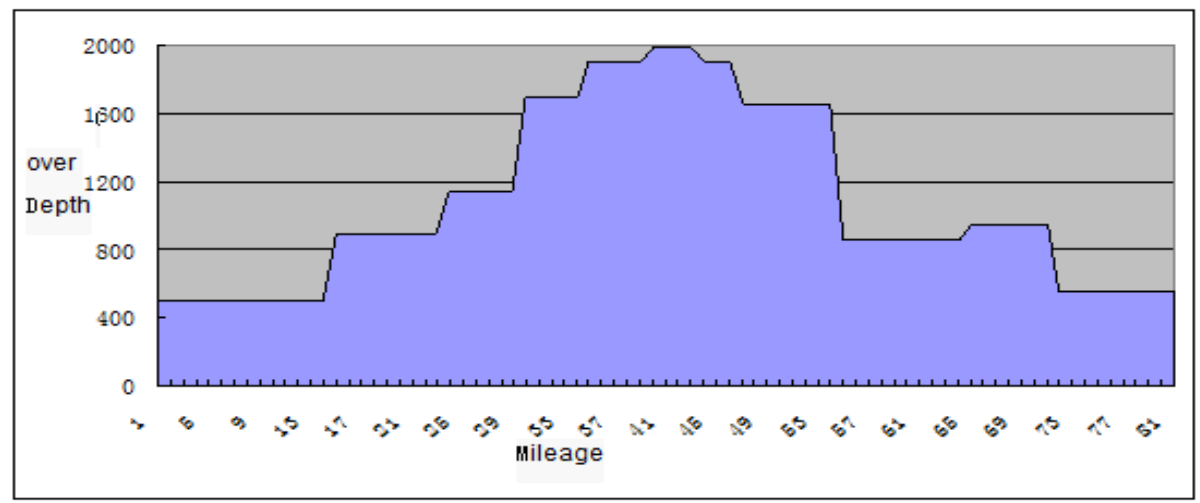

Fig.1 Schematic view of the tunnel's depth

2.2 Arrangement of test Section and test Method. The tests included temperature, humidity, sectional wind velocity and dust concentration under different working conditions and normal ventilation conditions. Test sections included the tunnel surface and $50 \mathrm{~m}, 100 \mathrm{~m}, 150 \mathrm{~m}$, et al. away from the tunnel face. Field test is shown in Fig.2
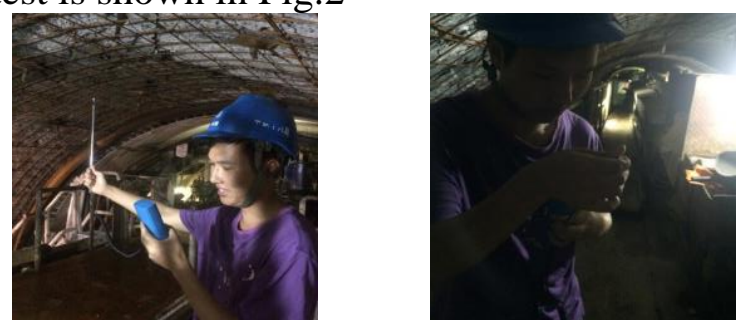

Fig.2 Field test

\section{Result of the Test and Analysis}

The field test results as shown in the figures below:

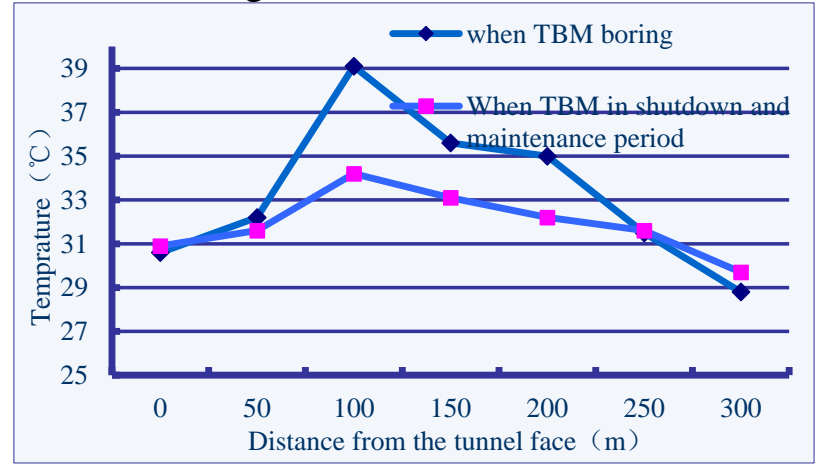

Fig.3 The tunnel's temperature distribution 


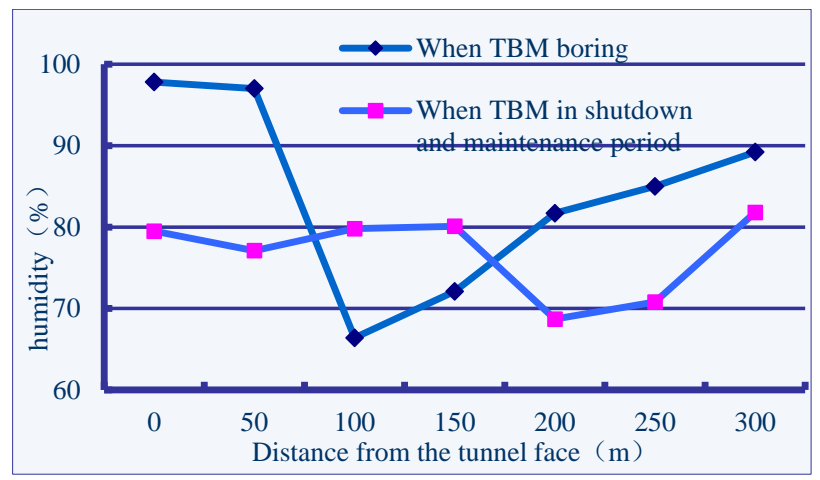

Fig.4 The tunnel's humidity distribution

Temperature distribution and humidity distribution in the tunnel are shown in Fig. 3 and Fig.4. Temperature rises at 100 meters away from the tunnel face when TBM is boring. This is because TBM electromechanical box will release a lot of heat. Similarly, humidity distribution is affected by TBM electromechanical box and Showing the opposite of the law.

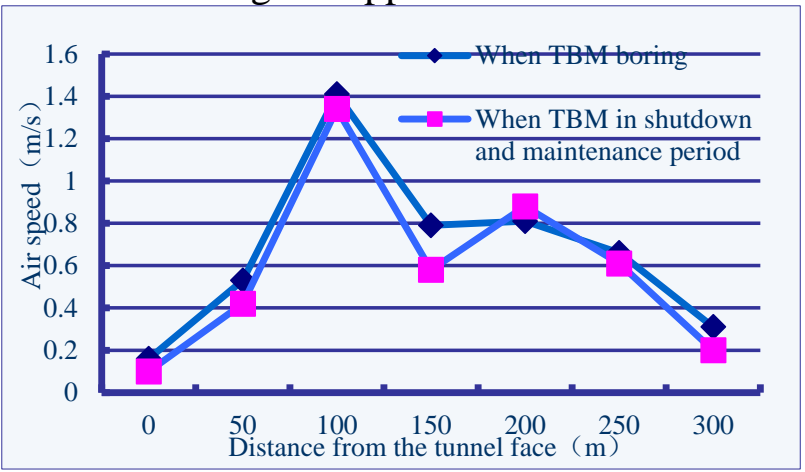

Fig.5 The tunnel's weed speed distribution

Fig. 5 shows that whether the TBM is boring or in shutdown maintenance period, in the $100 \mathrm{~m}$ distance from tunnel face, wind speed reaches the maximum value, $1.3 \mathrm{~m} / \mathrm{s}$. The test point is near the TBM electrical box radiating device.

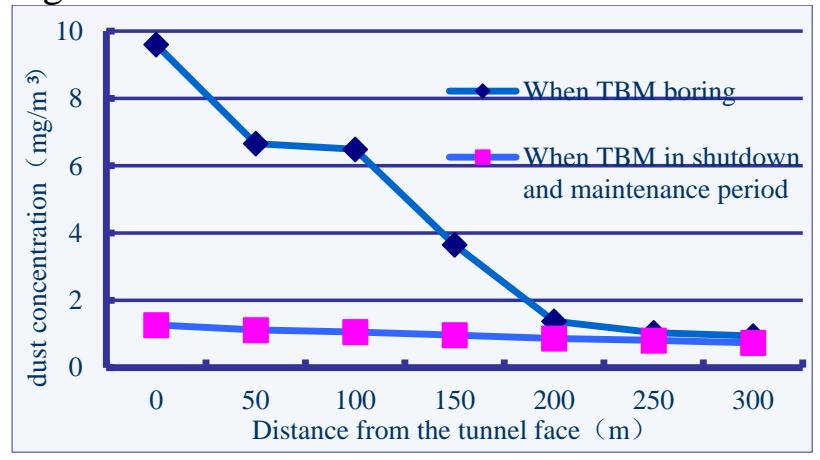

Fig .6 The tunnel's dust concentration distribution

Fig. 6 shows the tunnel's dust concentration distribution. The dust concentrations in the vicinity of the tunnel face is up to a maximum of $9.60 \mathrm{~g} / \mathrm{m}^{3}$. With the distance from the tunnel face increased, dust concentration is gradually decreased. In the TBM shutdown and maintenance period, dust concentration is stable at about $1.0 \mathrm{mg} / \mathrm{m}^{3}$. According to "highway tunnel construction technology standard "(JTG F60-2009), the total dust concentration is less than or equal to $10 \mathrm{mg} / \mathrm{m}^{3}$ in the construction process. The tunnel fan can meet the construction requirements under the two conditions.

\section{Suggestions}

According to the above test results, the tunnel excavation environment still cannot completely meet the construction specifications while using the most advanced excavation technology-TBM. Based on the results, the following suggestions are given for improving tunnel excavation environment:

(1) At present, the length of the air duct is too long, and the method of relay ventilation is 
recommended to reduce the distance of the wind pipe.

(2)Cooling and humidifying measures is proposed at working face to improve the working environment and ensure that the personnel work efficiency.

(3) When TBM boring, dust concentration near the tunnel face value close to the standard control value, regular watering device is recommended, to dust removal, improving the working environment of workers, ensuring t working efficiency.

\section{Conclusion}

The control values of temperature, humidity and wind speed are gained by statistics and analysis. In the Qinling TBM Tunnel, the tunnel temperature, humidity, wind speed can't meet the provisions of the construction specifications. Based on field test results of Qinling Tunnel, corresponding improvement measures of construction environment are proposed.

\section{Reference:}

1. TB 10003-2005 Code for construction on tunnel of railway [S].Beijing: China Railway Publishing House , 2005.

2. JTJ 026. 1-1999 Specifications for Design of Ventilation and Lighting of Highway Tunnel [S] Beijing: China Communications Press, 2000.

3. Yang Lixin, Hong Kairong, Liu Zhaowei,edg. Modern Tunneling Ventilation [M]. Beijing: China Communications Press, 2012.

4. Zhao Yihui. Mine Ventilation and Air Conditioning [M]. Xuzhou: China University of Mining and Technology press, 1990.

5. Zhang Guokuang. Ventilation Security [M]. Xuzhou: China University of Mining and Technology press, 2004.

6. Ye Xin. The Building Thermal Environment [M]. Beijing: Tsinghua University Press, 1995.

7. Xu Xiaolin, LI Baizhan, LUO Mingzhi. Influence of indoor thermal environment on thermal comfort of human body[J]. Refrigeration \& Air-condition, 2004( 4) :55-58. ( in Chinese)

8. Tian Yuanyuan, XU Weiquan. Experiment of human thermal response inwarm and humid environment[J]. Hv\&Ac, 2003, 33( 4) :27-30. ( in Chinese)

9. Yan Han. Environmental Protection and Management of Tunnel Engineering Construction Measures [M]. Railway Construction Technology, 2013. 